\title{
BMJ Open Health impact of objective burden, subjective burden and positive aspects of caregiving: an observational study among caregivers in Switzerland
}

Christine Fekete, ${ }^{1}$ Hannah Tough, ${ }^{1,2}$ Johannes Siegrist, ${ }^{3}$ Martin WG Brinkhof ${ }^{1,2}$

To cite: Fekete C, Tough H, Siegrist $\mathrm{J}$, et al. Health impact of objective burden, subjective burden and positive aspects of caregiving: an observational study among caregivers in Switzerland. BMJ Open 2017;7:e017369. doi:10.1136/ bmjopen-2017-017369

- Prepublication history for this paper is available online. To view these files, please visit the journal online (http://dx.doi. org/10.1136/bmjopen-2017017369).

Received 20 April 2017 Revised 7 August 2017

Accepted 21 September 2017

CrossMark

${ }^{1}$ Swiss Paraplegic Research, Nottwil, Switzerland

${ }^{2}$ Department of Health Sciences and Health Policy, University of Lucerne, Lucerne, Switzerland ${ }^{3}$ Faculty of Medicine, University of Duesseldorf, Life-ScienceCenter, Duesseldorf, Germany

Correspondence to

Dr Christine Fekete;

christine.fekete@paraplegie.ch

\section{ABSTRACT}

Objective To investigate associations of objective caregiver burden, subjective caregiver burden and positive aspects of caregiving with self-reported health indicators in caregiving partners of persons with a severe physical disability (spinal cord injury).

Design Cross-sectional, observational.

Setting Community, Switzerland.

Participants Caregiving partners of persons with spinal cord injury ( $n=118$, response rate $19.7 \%)$.

Outcome measures General health, role limitations due to physical health, role limitations due to mental health, pain intensity, mental health and vitality were assessed using items from the 36-Item Short Form Health Survey (SF-36). Three items were used to assess the frequency of different types of sleep problems.

Results Subjective caregiver burden was associated to all self-reported health indicators. A high subjective burden was linked to poorer general health $(0 \mathrm{R} 6.5,95 \% \mathrm{Cl} 2.0$ to 21.5$)$, more role limitations due to physical health (OR $4.2,95 \% \mathrm{Cl} 1.4$ to 12.8$)$, more role limitations due to mental health (OR 3.6, $95 \% \mathrm{Cl} 1.1$ to 11.7$)$, higher pain intensity (OR $4.0,95 \% \mathrm{Cl} 1.4$ to 11.5$)$, poorer mental health (coefficient $-17.9,95 \% \mathrm{Cl}-24.5$ to -11.2 ), lower vitality (coefficient $-20.3,95 \% \mathrm{Cl}-28.4$ to -12.1 ), and more frequent sleep problems (OR 5.3, $95 \% \mathrm{Cl} 1.6$ to 18.4 ). Partners who indicated positive aspects of caregiving further reported better mental health (coefficient 6.5, $95 \% \mathrm{Cl} 0.2$ to 12.8 ). Objective burden was not related to any health indicator.

Conclusions Subjective burden and lack of positive aspects of caregiving were associated with poorer physical and mental health. Caregiver health may be promoted through the strengthening of psychological and psychosocial resources.

\section{INTRODUCTION}

Informal caregiving for persons with physical disabilities is a chronic stressor that puts caregivers at risk for physical and mental morbidity. ${ }^{1}$ Providing informal care for a person with physical disability may be perceived as burdensome for a variety of reasons, including physical or mental demands, reduction in leisure time or

\section{Strength and limitations of this study}

- This study is among the first to analyse different dimensions of the caregiving experience with a comprehensive set of health indicators including physical and mental health in partners of persons with a severe physical disability.

- This study not only focuses on the negative aspects of caregiving in terms of burden, but also considers positive aspects of caregiving and their link to health.

- Causality regarding the caregiving experience and health cannot be inferred given the cross-sectional nature of data.

- The overall assessment of subjective caregiver burden used in this study may impose limitations on the results and subsequent interpretations for interventions, as it provides limited evidence on tangible sources of strain.

- Although sensitivity analysis support the robustness of findings, the small sample size and low response rate need to be considered in the interpretation of findings.

financial implications (eg, reduced capacity to engage in paid work). ${ }^{2}$ In contrast to professional caregivers, informal caregivers provide care without compensation or specific training. Persons with a spinal cord injury (SCI) are often in need of informal care $^{3}$ as SCI has an extensive impact on functioning which may lead to major disability. The burden of informal care is evidenced by the high prevalence of physical and emotional stress, fatigue, negative feelings and poor quality of life in caregivers for persons with SCI. ${ }^{4-7}$ Also, depression and anxiety disorders are common in SCI caregivers, with prevalence rates ranging from $16 \%$ to $53 \% .^{8-10}$

A comprehensive evaluation of the impact of informal care on caregivers' health needs to consider both, negative and positive aspects of the caregiving experience. Negative aspects of caregiving are commonly subsumed under the concept of caregiver burden, which 
includes an objective and a subjective component. ${ }^{11}$ While the objective burden of caregiving assesses the quantitative aspects that involve tangible currencies (eg, hours of care provided or tasks performed), the subjective burden captures the person's evaluation of strain resulting from the caregiver role. ${ }^{12}$ Given the multifaceted nature of subjective burden including physical, emotional, social or financial strain, a uniform conceptualisation is lacking. ${ }^{13}$ For instance, the internationally established Zarit Burden Interview (ZBI) integrates the perception of different stressors (eg, role conflicts, loss of autonomy or emotional strain) into a global unidimensional measure of subjective caregiver burden. ${ }^{13}$ The two components of objective and subjective burden are only moderately correlated and thus capture different aspects of the caregiving experience. ${ }^{12} 13$ Consequently, objective as well as subjective assessments of burden are needed for a comprehensive evaluation of the potential impact of caregiver burden on health. ${ }^{13}$ However, a general critique of this research field maintains that analyses are predominantly concentrated on 'strain' and less on 'gain', blaming the neglect of potential positive effects of caregiving. ${ }^{14}{ }^{15}$ For example, around three quarters of caregivers for elderly reported at least one positive aspect of caregiving, and these positive aspects were related to lower depression and better self-reported health in caregivers. ${ }^{16}$

Previous SCI caregiver literature is mainly focused on the description of the caregivers' tasks and roles, ${ }^{17} 18$ the physical and mental health of caregivers ${ }^{810} 19$ or the comparison of health between caregivers and non-caregivers, ${ }^{4720}$ neglecting the explicit link between caregiver burden and health. Moreover, the distinction between objective burden, subjective burden and positive aspects of caregiving is missing. To fill this gap, we investigate objective and subjective caregiver burden as well as positive aspects of caregiving as potential determinants of self-reported physical and mental health in caregiving partners of persons with SCI.

\section{METHODS}

\section{Sampling frame and participants}

Data used in this analysis came from the pro-WELL study, ${ }^{21}$ which is a nested study within the community survey of the Swiss Spinal Cord Injury Cohort Study (SwiSCI). ${ }^{22} 23$ This sampling frame included a representative population of 1922 persons aged over 16 years with traumatic or non-traumatic SCI living in Switzerland. ${ }^{22}{ }^{23}$ Of the 1922 SwiSCI participants, 676 persons were eligible for the pro-WELL study and 133 persons with SCI and their partners participated in the baseline assessment (response rate $19.7 \%$ ). Details on inclusion criteria, recruitment outcomes, participation rates and non-response are reported in the pro-WELL cohort profile. ${ }^{21}$

\section{Study design}

Pro-WELL is a longitudinal community survey with three measurement waves (baseline; month 6; month 12). In brief, the main objective of the pro-WELL study is to investigate associations of availability and quality of close social relationships and productive activities (eg, paid work, caregiving) with well-being in persons with SCI and their caregiving partners. Here, we used cross-sectional data from the baseline assessment carried out between May 2015 and January 2016. Data were collected by means of standardised telephone interviews, paper-pencil or online questionnaires. ${ }^{21}$

Regulations concerning informed consent and data protection were strictly observed and all participants signed an informed consent form.

\section{Measurements}

Objective caregiver burden was measured by self-report of caregiving partners regarding the daily hours of caregiving and type of help provided. ${ }^{24}$ Six selected items from the Personal Activities of Daily Living (ADL) Scale ${ }^{24}$ provided information on help with getting in and out of bed, using the toilet, dressing, bathing or showering, eating and mobility within the home. A further five items captured information on help with instrumental ADL (IADL), including help with doing the shopping, doing housework, managing money and paying bills, preparing meals and providing transportation. Response options for the 11 items on type of help provided were "no help provided' (0), 'some help provided' (1) and 'much help provided' (2). A sum score ranging from 0 to 12 for ADL and $0-10$ for IADL was created.

Subjective caregiver burden was measured with the Zarit Burden Interview (ZBI) ${ }^{25}$ short form $(\mathrm{S})^{26}$ that has recently been validated in SCI caregivers. ${ }^{27}$ The ZBI-S includes 12 items on personal feelings of strain resulting from the caregiving role. The five-point response scale includes the options: never, rarely, sometimes, frequently or nearly always. A sum score ranging from 0 to 48 was calculated. Based on Schreiner et al, ${ }^{28}$ sum scores $\leq 12$ were classified as low and scores $>12$ as high burden. In our sample, this cut-off separates the upper burden quintile from the rest which enables the comparison of health effects in highly distressed caregivers and caregivers with lower distress. In sensitivity analysis, regression models were additionally computed with the continuous ZBI sum score.

Positive aspects of caregiving were assessed by two items on the degree of agreement to the statements 'to care for my partner gives my life a deeper sense' and 'the care of my partner gives me a feeling of satisfaction'. Response options were completely disagree (0), disagree (1), agree (2) and completely agree (3). Mean scores were calculated and scores of $\geq 2$ were coded as 'deeper sense or satisfaction from caregiving' and scores $<2$ as 'no deeper sense or satisfaction from caregiving'.

Health indicators. To assess general health, a single item with a five-point scale (very good, good, neither good nor bad, bad, very bad) was used. Mental health, vitality, role limitations due to physical and mental health and pain intensity were assessed using the 36-Item Short Form Health Survey (SF-36) V.1. ${ }^{29}$ The five items on 
Table 1 Basic characteristics of caregiving partners included in the baseline assessment of the pro-WELL study $(n=118)$

\begin{tabular}{|c|c|c|}
\hline Variable [missing values] & n (\%) & Mean (SD) \\
\hline \multicolumn{3}{|l|}{$\begin{array}{l}\text { Sociodemographic } \\
\text { characteristics }\end{array}$} \\
\hline Age in years [0] & & $50.7(10.0)$ \\
\hline Male gender [0] & $32(27.1)$ & \\
\hline Female gender & $86(72.9)$ & \\
\hline Partnership before SCI [7] & $50(45.0)$ & \\
\hline $\begin{array}{l}\text { Duration of partnership in } \\
\text { years [5] }\end{array}$ & & $24.0(12.8)$ \\
\hline $\begin{array}{l}\text { Time since caregiving in } \\
\text { years [7] }\end{array}$ & & $18.8(11.0)$ \\
\hline Hours of paid work per week [6] & & $27.1(11.8)$ \\
\hline Having paid work & $81(68.6)$ & \\
\hline Some financial hardship [5] & $39(34.5)$ & \\
\hline No financial hardship & $74(65.5)$ & \\
\hline
\end{tabular}

Lesion characteristics of the

care receiver

\begin{tabular}{|c|c|c|}
\hline $\begin{array}{l}\text { Lesion level and } \\
\text { completeness [2] }\end{array}$ & & \\
\hline Incomplete paraplegia & $36(31.0)$ & \\
\hline Complete paraplegia & $45(38.8)$ & \\
\hline Incomplete tetraplegia & $22(19.0)$ & \\
\hline Complete tetraplegia & $13(11.2)$ & \\
\hline Traumatic aetiology [3] & 97 (84.3) & \\
\hline Non-traumatic aetiology & $18(15.7)$ & \\
\hline Time since injury in years [5] & & $24.7(11.7)$ \\
\hline Objective caregiver burden & & \\
\hline Daily hours of caregiving [12] & & $2.0(3.5)$ \\
\hline Less than an hour & $32(30.2)$ & \\
\hline Around an hour & $33(31.1)$ & \\
\hline Around 2 to 3 hours & $26(24.5)$ & \\
\hline Over 3 hours & $15(14.2)$ & \\
\hline $\begin{array}{l}\text { Amount of ADL support, range } \\
0-12 \text { [6] }\end{array}$ & & $2.4(3.0)$ \\
\hline Lowest tertile $(0)$ & $41(36.6)$ & \\
\hline Middle tertile (1-2) & $36(32.1)$ & \\
\hline Highest tertile $(\geq 3)$ & 35 (31.3) & \\
\hline $\begin{array}{l}\text { Amount of IADL support, range } \\
0-10 \text { [10] }\end{array}$ & & $4.1(2.7)$ \\
\hline Lowest tertile (0-2) & $40(37.0)$ & \\
\hline Middle tertile (3-4) & 38 (35.2) & \\
\hline Highest tertile $(\geq 5)$ & $30(27.8)$ & \\
\hline Subjective caregiver burden & & \\
\hline ZBI-S, range 0-48 [5] & & $7.4(7.2)$ \\
\hline Lower burden (0-12) & $91(80.5)$ & \\
\hline Higher burden (>12) & $22(19.5)$ & \\
\hline
\end{tabular}

Continued
Table 1 Continued

\begin{tabular}{|c|c|c|}
\hline Variable [missing values] & n (\%) & Mean (SD) \\
\hline \multicolumn{3}{|l|}{ Positive aspects of caregiving } \\
\hline $\begin{array}{l}\text { Deeper sense or } \\
\text { satisfaction [17] }\end{array}$ & $40(39.6)$ & \\
\hline $\begin{array}{l}\text { No deeper sense or } \\
\text { satisfaction }\end{array}$ & $61(60.4)$ & \\
\hline \multicolumn{3}{|l|}{ Health indicators } \\
\hline $\begin{array}{l}\text { Good or very good general } \\
\text { health [2] }\end{array}$ & $82(70.7)$ & \\
\hline Less than good health & $34(29.3)$ & \\
\hline $\begin{array}{l}\text { No role limitations due to } \\
\text { physical health [3] }\end{array}$ & $67(58.3)$ & \\
\hline Some role limitations & $48(41.7)$ & \\
\hline $\begin{array}{l}\text { No role limitations due to } \\
\text { mental health [5] }\end{array}$ & $87(77.0)$ & \\
\hline Some role limitations & $26(23.0)$ & \\
\hline No sleep problems [4] & $50(43.9)$ & \\
\hline One sleep problem & $26(22.0)$ & \\
\hline Two sleep problems & $20(17.0)$ & \\
\hline Three sleep problems & $18(15.3)$ & \\
\hline No or mild pain intensity [4] & $81(71.1)$ & \\
\hline At least moderate pain & $33(29.0)$ & \\
\hline Mental health, range $0-100[4]$ & & $59.1(18.1)$ \\
\hline Vitality, range 0-100 [4] & & $73.9(15.6)$ \\
\hline
\end{tabular}

$A D L$, activities of daily living; IADL, informal activities of daily living; $\mathrm{SCl}$, spinal cord injury; ZBI-S, Zarit Burden Interview, short form.

mental health and the four items on vitality assessed the frequency of specific mental and vital states. ${ }^{29}$ The six-point response options ranged from 'all of the time' to 'none of the time'. A sum score ranging from 0 to 100 was computed according to established algorithms for both subscales, ${ }^{30}$ with higher scores indicating better mental health and vitality. The four items on role limitations due to physical health and the three items on role limitations due to mental health were rated on a binary scale (yes, no). A six-point item on pain intensity during the past 4 weeks was used to assess pain (none, very mild, mild, moderate, strong, very strong). Additionally, three items on the frequency of problems with falling asleep, waking up during the night or waking up earlier than usual were used to assess sleep problems. The four response options included: never, sometimes (once a week or less), every now and then (at least twice a week) or almost every night. The ordinal variables on general health, role limitations due to physical and mental health and pain intensity were dichotomised due to low sample size in some response options. The following cut-points were applied: less than good general health versus good or very good general health; some role limitations versus no role limitations due to mental or physical health; no, very light or light pain versus moderate, strong or very strong pain. Each 


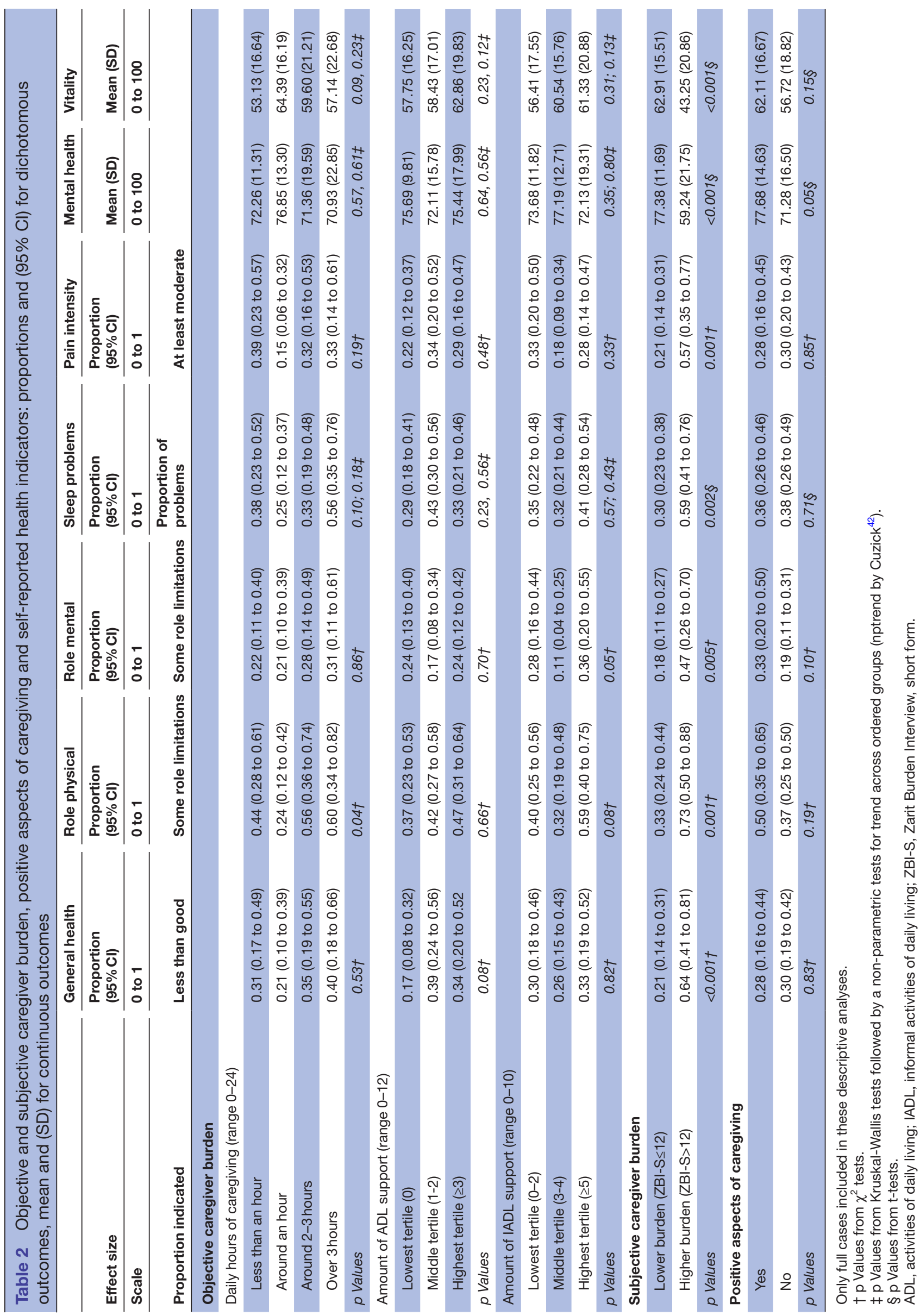


of the three items on frequency of sleep problems was dichotomised (never or sometimes; every now and then or almost every night). Mental health and vitality were used as continuous outcomes $(0-100){ }^{30}$

Potential confounders. Based on the caregiver literature, age, gender, lesion characteristics of the care receiver (paraplegia, tetraplegia; complete lesion, incomplete lesion; aetiology), time since caregiving and hours of engagement in paid work were introduced as potential confounders in multivariable models. Given the relationship with health in a Swiss SCI population, ${ }^{31}$ financial hardship was additionally controlled for. Financial hardship was assessed with a single item on how subjects evaluate the availability of their financial resources on a five-point scale (very scarce, scarce, just lasts, last good, last very good).

\section{Statistical analyses}

Analyses were conducted using STATA V.14.0 for Windows (College Station, Texas, USA). Distributions of included study variables were evaluated and correlations among measures of objective burden, subjective burden and positive aspects of caregiving were computed. Further, cross-tabulations were performed to investigate bivariable associations of objective burden, subjective burden and positive aspects of caregiving with self-reported health indicators. We report proportions and binominal 95\% CI for dichotomous and mean and SD for continuous health indicators. For sleep problems, we calculated an average probability across the three items.

Logistic and tobit regressions were applied to derive unadjusted or adjusted estimates of associations between the predictors (objective and subjective caregiver burden, positive aspects of caregiving) and the outcomes (health indicators). Logistic regression was applied for general health, role limitations due to physical and mental health and pain intensity. The three types of sleep problems were considered as repeated measures within the individual and analysed using a mixed-model logistic regression with participant identification as random intercept. Tobit models were applied for the continuous and right censored scores of mental health and vitality. ${ }^{32}$ Two subsequent models were computed: model 1 was unadjusted; model 2 was adjusted for age, gender, lesion characteristics of the care receiver, time since caregiving, hours of paid work and financial hardship.

Multiple imputation was used to account for item non-response assuming missingness at random. Although we were not able to validate the assumption that data were missing at random, it is still preferable to impute missing values instead of performing full case analysis. ${ }^{33}$ We applied multiple imputation by chained equations to impute different types of variables, including categorical, ordinal and linear variables. ${ }^{27}$ All missing values of predictors were imputed. Imputations were carried out for 10 datasets for each model and distributions of imputed values were reviewed for plausibility. In respective tables, ORs (for logistic regressions) and $\beta$ coefficients (for tobit regressions), $95 \% \mathrm{CI}$ and $\mathrm{p}$ values from the equal fraction-missing-information (FMI) test are presented. ${ }^{34}$ The FMI indicates the amount of variance attributable to missing data. When using an FMI test, it is assumed that the between-imputation variance is proportional to the within-imputation variance and a subset of variables are tested for significance by jointly testing whether coefficients are equal to zero. The $\mathrm{p}$ values can therefore be interpreted much the same as others, in that a significant value indicates that the predictor is significantly associated with the outcome.

In light of the limited sample size of the study, we tested the robustness of the multivariable results using the bootstrap method as part of sensitivity analysis. Bootstrap inference was based on 10000 replicates with replacement, combining results over imputed datasets using the MI-Boot-pooled method. ${ }^{35}$

\section{RESULTS}

Around three quarters of caregiving partners were female and mean age was around 50 years. Nearly half of participants were in a relationship before SCI, mean length of partnership was 24 years and the average duration of caregiving was 19 years. About two-thirds of caregivers had paid employment, with a mean workload of 27 hours per week. One-third of the sample indicated some financial hardship. A large proportion of care receivers had a traumatic SCI and complete paraplegia was the most frequent diagnosis. Mean time since injury of care receivers was around 25 years. The average duration of daily care provided was 2 hours. Support in IADL tasks was more frequent than support in ADL tasks. On average, caregivers scored their subjective burden around 7.4, and nearly $20 \%$ of caregivers were classified into the high burden group. Around $60 \%$ indicated to experience no positive aspects of caregiving. Almost 30\% of caregivers described their general health as less than good, over $40 \%$ indicated role limitations due to physical health and 23\% indicated role limitations due to mental health. Around $54 \%$ of caregivers reported at least one sleep problem and almost $30 \%$ of the caregivers indicated moderate or severe pain. On a range from 0 to 100 , caregivers rated their mental health on average with 59 and their vitality with 74 (table 1).

Weak to moderate correlations between measures of objective burden, subjective burden and positive aspects of caregiving were observed, supporting the notion that these concepts measure different dimensions of the caregiving experience. The three measures of objective burden (hours of caregiving, amount of ADL, IADL support) were moderately correlated, with coefficients ranging from 0.49 to 0.70 . Coefficients for the correlation between objective and subjective burden ranged from 0.07 to 0.40 , and positive aspects of caregiving were weakly related to objective and subjective burden (coefficients between -0.10 and 0.19 ). 


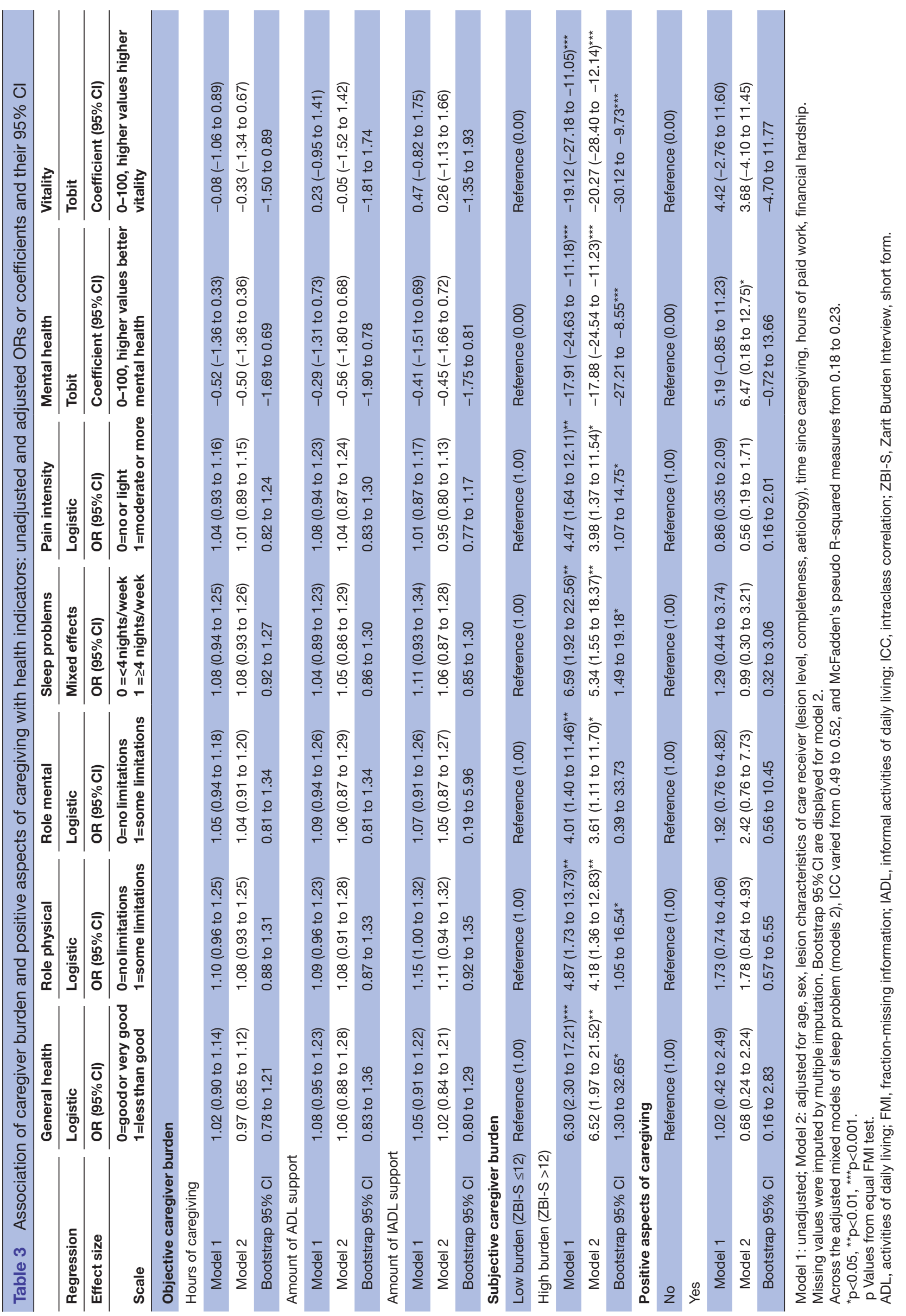

० 0 ए ए

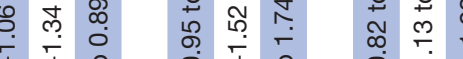

m d

$\frac{1}{0}$

O

อ กิ

$\circ$ 요

王织织

토

운

ธ。 Љ

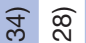

요 우

$\circ \circ$

Гᄃ $\stackrel{\infty}{\infty}$

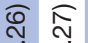

우 우

5

눙 운

ब్ల శ్ల

$\circ$ 요

每

다 ᄃ ๙

ลูก

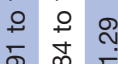

อ อ 요

菅

$\overline{0}$

丁

인

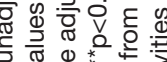

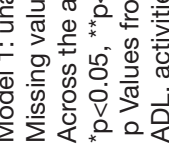

$\frac{\bar{c}}{3}$

음

음

๖े

욱

을.

กั

ก

స్ల

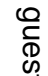

뭉

离 
Bivariable analysis showed that objective caregiver burden was not related to any health indicator, while high subjective burden was related to poorer health in all studied indicators. Furthermore, caregivers who experienced positive aspects of caregiving rated their mental health higher than those not experiencing positive aspects (table 2).

Results from adjusted analysis indicate that objective burden was not related to any health indicator, whereas subjective burden was associated to all health indicators and positive aspects of caregiving were linked to mental health. Caregivers who report a high subjective burden had 6.5-fold increased odds to rate their health as less than good, 4.2-fold increased odds of experiencing role limitations due to physical health and 3.6-fold increased odds of experiencing role limitations due to mental health compared with caregivers with lower subjective burden. Caregivers in the high burden group had 5.3 times higher odds of having frequent sleep problems and 4.0 times higher odds of experiencing moderate or severe pain than those in the lower burden group. On a scale from 0 to 100 , caregivers with high subjective burden rated their mental health and vitality on average 17.9 and 20.3 points lower than those with lower burden. In contrast, those who experienced positive aspects of caregiving scored their mental health 6.5 points higher than those not experiencing positive aspects (table 3 ).

\section{Sensitivity analyses}

Bootstrap analyses confirmed the robustness of multivariable findings on the association between subjective burden and health in six out of seven indicators, while the link between positive aspects of caregiving and mental health appeared less robust (table 3). Sensitivity analysis using the ZBI sum score as continuous predictor fully supported the results of multivariable analyses (results not shown).

\section{DISCUSSION}

This study in the context of SCI provides evidence that the subjective perception of burden resulting from caregiving is associated with physical and mental health of caregivers, while the amount of care and tasks provided were not related to caregivers' health. Furthermore, we found that partners who experienced positive aspects of caregiving rated their mental health higher than those not reporting positive aspects. These findings are novel for the SCI literature as previous caregiver studies were rather descriptive in nature 4810171920 and the link between caregiver burden and health has not been reported yet.

Our findings provide an important contribution to the growing body of evidence regarding the relative importance of objective and subjective caregiver burden on health. Results from a meta-analysis including over 8000 caregivers showed inconsistent associations with objective caregiver burden, indicating for example that hours of care provision was related to depression but not to physical health. ${ }^{36}$ In turn, a meta-analysis of 118 studies with over 21000 caregivers demonstrated that caregivers with higher subjective burden are at risk of reduced physical health and increased depression. ${ }^{36}$ Comparable to our findings, this meta-analysis indicates a consistent association between subjective burden and physical as well as mental health. The minimum clinically important differences (MCID) of 5 points were reported for the $0-100$ scales of SF-36. ${ }^{37}$ The observed differences of 18 (mental health) and 20 points (vitality) between caregivers with high versus low subjective burden can thus be interpreted as clinically relevant. Since systematic investigations of MCID for other SF-36 subscales are currently unavailable, we were not able to further interpret findings in light of clinical importance. Notably, our findings underpin the importance of a conceptual distinction between objective and subjective burden in caregiver research. This distinction is important to understand potential causal pathways linking caregiver burden to health as to identify specific targets for intervention.

A traditional definition maintains that stress is a specific 'relationship between the person and the environment that is appraised by the person as taxing or exceeding his or her resources and endangering well-being ${ }^{, 38}(\mathrm{p}$ 19). The objective amount of caregiving might not be appraised as particularly stressful per se, if persons have sufficient psychological (eg, high self-efficacy, locus of control) or psychosocial (eg, social support) resources for coping with stress. Only if caregiving tasks are appraised as exceeding available resources, this may result in subjective feelings of burden or strain, independently of the amount of care provided. The fact that the correlation between objective and subjective caregiver burden is only weak to moderate in our sample supports the argument that caregiver burden is related to health as far as it is appraised as stressful. The impact of stress on health has been widely analysed, suggesting that psychological distress, such as caregiver burden, negatively impacts hormonal changes, increases susceptibility to infectious agents and favours health adverse behaviour. ${ }^{39}$

Our study supports the importance of positive aspects of caregiving observed previously ${ }^{16}$ as caregivers reporting positive aspects indicated better mental health as compared with caregivers not reporting positive aspects of their caregiving experience. Positive aspects of caregiving may reflect a further target for interventions that aim to improve mental health of caregivers. However, sensitivity analysis indicated inconclusive robustness of findings, potentially due to the limited sample size of our study. Furthermore, none of the physical health indicators was associated with positive aspects of caregiving, and we could therefore not conclude that positive experiences of caregiving buffer the stress-related consequences on physical health. ${ }^{40}$

Future research should elaborate the different sources of strain and their consequences on caregivers' health. The ZBI provides a summary measure of different dimensions 
of strain such as conflicts with other role obligations, reduced personal autonomy or negative emotions in the presence of the care recipient. It would be worthwhile to disentangle these dimensions and to study their separate effects on health as to identify the most relevant targets for intervention. ${ }^{113}$ Moreover, it is essential to further investigate the role of additional resources and strains that may moderate the relationship between subjective burden and health. For example, the role of relationship quality, ${ }^{41}$ social support or socioeconomic circumstances in determining caregiver burden and caregiver health is not well understood.

Our findings may suggest potential avenues for future intervention research that seeks to develop strategies to improve health of caregivers. Potential strategies may include the reduction of stressful experiences through improvement of psychological and psychosocial resources and the strengthening of a sense of gratification and purpose associated with the caregiver role. Interventions aimed at enhancing coping skills of SCI caregivers demonstrate promising results. Problem-solving interventions were effective in reducing depression and health symptoms and in increasing social functioning and quality of life in SCI caregivers. ${ }^{15}$ Further, an outpatient support group intervention was found to increase general health, mental health and quality of life of SCI caregivers. ${ }^{15}$

\section{Strength and limitations}

A major strength of this study is the use of a comprehensive set of health indicators, including physical and mental health, mostly assessed with validated scales. All associations were tested using state-of-the-art multivariable statistical methods, taking into account relevant confounders. To overcome potential methodological limitations due to low sample size, sensitivity analyses using bootstrap techniques were performed, confirming most of our findings. Furthermore, the pro-WELL study was nested in a large cohort study, showing good representation of the source population of care receivers in terms of socio demographic and lesion characteristics. ${ }^{21}$

Several limitations need to be considered when interpreting the results of this study. First, the directionality regarding the association between the caregiving experience and health cannot be conclusively inferred given the cross-sectional nature of data. Second, our sample is relatively small, and the response rate was rather low. ${ }^{21}$ Nevertheless, sensitivity analyses revealed good robustness of findings and non-response analyses on basic characteristics of care receivers indicated a non-biased representation of the source population in terms of sociodemographic and lesion characteristics. ${ }^{21}$ Third, the unidimensionality of the instrument used to assess subjective caregiver burden in this study may impose several limitations on the results and subsequent interpretations for interventions, as it only provides an overall assessment of subjective burden and does not help identifying tangible sources of strain. ${ }^{13}$ Fourth, constraints on questionnaire length did not allow for the inclusion of a comprehensive and validated scale to assess positive aspects of caregiving. Following positive aspects of caregiving might be poorly captured in this study. Fifth, functional capacity of caregivers was not assessed in the pro-WELL study. We were thus unable to control the associations between the caregiving experience and health for potential confounding by caregiver capacity.

We conclude that caregivers' physical and mental health can be strengthened by enhancing psychological and psychosocial resources to reduce the subjective strain resulting from the caregiver role. Furthermore, strengthening the feeling that the care for their partner has positive aspects may enhance mental health of caregiving partners.

Acknowledgements We are grateful to all the participants of the pro-WELL study for their time and effort spent in responding to our questions and to the research assistants for their great work in recruitment and data collection. We also acknowledge the support from the Steering Committee of the SwiSCl cohort study.

Collaborators Despite a relatively small sample size, this study offers options of scientific collaborations. We therefore invite researchers to contact the corresponding author for further arrangements.

Contributors The pro-WELL study was designed by JS and CF. CF and MWGB developed the research question of this analysis, analysed the data and interpreted the results. CF wrote the first draft of the manuscript and all authors worked on, reviewed and approved the final version of the manuscript.

Funding This study has been financially supported by the Swiss National Science Foundation, grant number 100017_153256/1 and by the Swiss Paraplegic Foundation, Nottwil Switzerland.

Competing interests None declared.

Patient consent Obtained.

Ethics approval The study protocol and all measurement instruments were approved by the Ethical Committee of Northwest and Central Switzerland (document EKNZ 2014-285).

Provenance and peer review Not commissioned; externally peer reviewed. Data sharing statement No additional data are available.

Open Access This is an Open Access article distributed in accordance with the Creative Commons Attribution Non Commercial (CC BY-NC 4.0) license, which permits others to distribute, remix, adapt, build upon this work non-commercially, and license their derivative works on different terms, provided the original work is properly cited and the use is non-commercial. See: http://creativecommons.org/ licenses/by-nc/4.0/

(C) Article author(s) (or their employer(s) unless otherwise stated in the text of the article) 2017. All rights reserved. No commercial use is permitted unless otherwise expressly granted.

\section{REFERENCES}

1. Schulz R, Sherwood PR. Physical and mental health effects of family caregiving. Am J Nurs 2008;108(9 Suppl):23-7.

2. Schulz R, Martire LM. Family caregiving of persons with dementia: prevalence, health effects, and support strategies. Am J Geriatr Psychiatry 2004;12:240-9.

3. Bickenbach J, Officer A, Shakespeare T, et al. International perspectives on spinal cord injury. Geneva: WHO, 2013.

4. Weitzenkamp DA, Gerhart KA, Charlifue SW, et al. Spouses of spinal cord injury survivors: the added impact of caregiving. Arch Phys Med Rehabil 1997;78:822-7.

5. Shewchuk RM, Richards JS, Elliott TR. Dynamic processes in health outcomes among caregivers of patients with spinal cord injuries. Health Psychol 1998;17:125-9.

6. Manigandan C, Saravanan B, Macaden A, et al. Psychological wellbeing among carers of people with spinal cord injury: a preliminary investigation from South India. Spinal Cord 2000;38:559-62. 
7. Unalan $\mathrm{H}$, Gençosmanoğlu B, Akgün $\mathrm{K}$, et al. Quality of life of primary caregivers of spinal cord injury survivors living in the community: controlled study with short form-36 questionnaire. Spinal Cord 2001;39:318-22.

8. Dreer LE, Elliott TR, Shewchuk R, et al. Family caregivers of persons with spinal cord injury: predicting caregivers at risk for probable depression. Rehabil Psychol 2007;52:351-7.

9. Raj JT, Manigandan C, Jacob KS. Leisure satisfaction and psychiatric morbidity among informal carers of people with spinal cord injury. Spinal Cord 2006;44:676-9.

10. Rodakowski J, Skidmore ER, Rogers JC, et al. Does social support impact depression in caregivers of adults ageing with spinal cord injuries? Clin Rehabil 2013;27:565-75.

11. Bastawrous M. Caregiver burden-a critical discussion. Int J Nurs Stud 2013:50:431-41.

12. Montgomery RJV, Gonyea JG, Hooyman NR. Caregiving and the experience of subjective and objective burden. Fam Relat 1985;34:19-26.

13. Chou K-R, Chu H, Tseng C, et al. The measurement of caregiver burden. J Med Sci 2003;23:73-82.

14. Hunt CK. Concepts in caregiver research. J Nurs Scholarsh 2003;35:27-32.

15. Baker A, Barker S, Sampson A, et al. Caregiver outcomes and interventions: a systematic scoping review of the traumatic brain injury and spinal cord injury literature. Clin Rehabil 2017;31:45-60.

16. Cohen CA, Colantonio A, Vernich L. Positive aspects of caregiving: rounding out the caregiver experience. Int J Geriatr Psychiatry 2002; $17: 184-8$.

17. Post MW, Bloemen J, de Witte LP. Burden of support for partners of persons with spinal cord injuries. Spinal Cord 2005;43:311-9.

18. Charlifue SB, Botticello A, Kolakowsky-Hayner SA, et al. Family caregivers of individuals with spinal cord injury: exploring the stresses and benefits. Spinal Cord 2016;54:732-6.

19. Middleton JW, Simpson GK, De Wolf A, et al. Psychological distress, quality of life, and burden in caregivers during community reintegration after spinal cord injury. Arch Phys Med Rehabil 2014:95:1312-9.

20. LaVela SL, Landers K, Etingen B, et al. Factors related to caregiving for individuals with spinal cord injury compared to caregiving for individuals with other neurologic conditions. J Spinal Cord Med 2015;38:505-14.

21. Fekete $\mathrm{C}$, Brinkhof MW, Tough $\mathrm{H}$, et al. Longitudinal study of social participation and well-being among persons with spinal cord injury and their partners (pro-WELL). BMJ Open 2017;7:e011597.

22. Brinkhof MW, Fekete C, Chamberlain JD, et al. Swiss nationa community survey on functioning after spinal cord injury: Protocol, characteristics of participants and determinants of non-response. J Rehabil Med 2016;48:120-30.

23. Fekete C, Segerer W, Gemperli A, et al. Participation rates, response bias and response behaviours in the community survey of the Swiss Spinal Cord Injury Cohort Study (SwiSCl). BMC Med Res Methodol 2015;15:80.
24. Schofield HL, Murphy B, Herrman HE, et al. Family caregiving: measurement of emotional well-being and various aspects of the caregiving role. Psychol Med 1997;27:647-57.

25. Zarit SH, Reever KE, Bach-Peterson J. Relatives of the impaired elderly: correlates of feelings of burden. Gerontologist 1980;20:649-55

26. Bédard M, Molloy DW, Squire L, et al. The Zarit Burden Interview: a new short version and screening version. Gerontologist 2001:41:652-7.

27. Rajabi-Mashhadi MT, Mashhadinejad $\mathrm{H}$, Ebrahimzadeh $\mathrm{MH}$, et al The Zarit Caregiver Burden Interview Short Form (ZBI-12) in spouses of veterans with chronic spinal cord injury, validity and reliability of the Persian version. Arch Bone Jt Surg 2015;3:56-63.

28. Schreiner AS, Morimoto T, Arai $Y$, et al. Assessing family caregiver's mental health using a statistically derived cut-off score for the Zarit Burden Interview. Aging Ment Health 2006;10:107-11.

29. Ware JE, Sherbourne CD. The MOS 36-item short-form health survey (SF-36). I. Conceptual framework and item selection. Med Care 1992;30:473-83.

30. Ware JE, Snow KK, Kosinski M, et al. SF-36 Health Survey. Manual and interpretaion guide. Massachusetts: The Health Institute, New England Medical Center, 1993.

31. Fekete C, Siegrist J, Reinhardt JD, et al. Is financial hardship associated with reduced health in disability? The case of spinal cord injury in Switzerland. PLoS One 2014;9:e90130.

32. Tobin J. Estimation of relationships for limited dependent variables. Econometrica 1958;26:24-36.

33. Carpenter J, Kenward M. Multiple imputation and its application. Hoboken, New Jersey: Wiley, 2013.

34. Li K-H RT, Rubin D. Large-sample significance levels from multiply imputed data using moment-based statistics and an $\mathrm{F}$ reference distribution. J Am Stat Assoc 1991;86:1065-73.

35. Schomaker M, Heumann C. Bootstrap inference when using multiple imputation: Cornell University Library, 2016.

36. Pinquart M, Sörensen S. Correlates of physical health of informal caregivers: a meta-analysis. J Gerontol B Psychol Sci Soc Sci 2007;62:P126-P137.

37. Ware J, Kosinski M, Gandek B. SF-36 Health Survey: manual and interpretation quide. RI QualityMetric: Lincoln, 2005.

38. Lazarus RS, Folkman S. Stress, appraisal, and coping. New York: Springer, 1984

39. Vitaliano PP, Zhang J, Scanlan JM. Is caregiving hazardous to one's physical health? A meta-analysis. Psychol Bull 2003;129:946-72.

40. Roth DL, Fredman L, Haley WE. Informal caregiving and its impact on health: a reappraisal from population-based studies. Gerontologist 2015:55:309-19.

41. Tough H, Brinkhof MW, Siegrist J, et al. Subjective Caregiver Burden and Caregiver Satisfaction: The Role of Partner Relationship Quality and Reciprocity. Arch Phys Med Rehabil. In Press. 2017;98:2042-51.

42. Cuzick J. A Wilcoxon-type test for trend. Stat Med 1985;4:87-90 